\title{
Flow Boiling Heat Transfer in Coated and Uncoated Plate Heat Exchangers
}

\author{
Angela Mutumba ${ }^{1 *}$, Tassos Karayiannis ${ }^{1}$, Francesco Coletti ${ }^{2}$, Alex Reip ${ }^{3}$ \\ ${ }^{1}$ Department of Mechanical and Aerospace Engineering, Brunel University London \\ Uxbridge, Middlesex UB8 3PH, UK \\ Angela.Mutumba@brunel.ac.uk; Tassos.Karayiannis@brunel.ac.uk \\ ${ }^{2}$ Department of Chemical Engineering, Brunel University London \\ Uxbridge, Middlesex UB8 3PH, UK \\ ${ }^{3}$ Oxford nanoSystems \\ Abingdon Business Park, OX14 1DY, Oxford, UK
}

\section{Extended Abstract}

The research community is currently focused on developing next generation technological solutions to utilise the energy available in domestic and industrial waste. The recoverable energy could be significant; for example, a recent study in the UK [1] identified $48 \mathrm{TWh} /$ year of recoverable waste heat (17\% of all industrial energy use). Organic Rankine Cycles (ORC) are best suited to harness this waste heat as they convert low and medium grade waste heat to power $\left(<100{ }^{\circ} \mathrm{C}\right.$ to $\left.300-400{ }^{\circ} \mathrm{C}\right)$. It is noteworthy that the potential work output and cycle efficiency, typically $16 \%$ [2], are limited by the efficiencies of the heat exchangers. Therefore improving the performance of heat exchangers in ORCs could make the utilisation of waste heat a viable concept. Plate heat exchangers (PHEs) are widely used in numerous industrial processes owing to their compact size, high surface area to volume ratio and consequently improved thermal performance, thus making them key possible component in ORCs. Although there has been numerous experimental work on the boiling of refrigerants inside PHEs, there is still a great challenge in overcoming the overall interfacial thermal-resistances between the plates that could result in significant improvements in the overall heat transfer coefficient. Boiling heat transfer can be significantly enhanced by modifying the surface characteristics. This passive enhancement technique has been investigated and applied widely in for example, shell and tube heat exchangers and less in plate heat exchangers.

The performance of a brazed PHE with water as the single phase heat source and R245fa in single phase and in flow boiling mode on the other side was studied. The refrigerant-side surface was then coated and the experimental results were compared with the as-supplied heat exchanger in terms of heat transfer rates and pressure drop. The nanoFLUX® coating is a proprietary coating consisting of a metallic dendritic nano and micro structure allowing for optimisable porosity for refrigerant bubble nucleation. The results were also compared with the small number of correlations predicting the heat transfer rates on the refrigerant side and the overall heat transfer coefficient of the heat exchangers. Final recommendations for design including the possible enhancement due to the coating will be presented.

\section{References}

[1] DECC, "The potential for recovering and using surplus heat from industry," 2014.

[2] Quoilin, S., Van Den Broek, M., Declaye, S., Dewallef, P. and Lemort, V., "Techno-economic survey of Organic Rankine Cycle (ORC) systems," Renewable and Sustainable Energy Reviews, 22, pp.168-186, 2013. 